\title{
Efficacy, Safety, and Tolerability of Low-Dose Hormone Therapy in Managing Menopausal Symptoms
}

\author{
Robert D. Langer, $M D, M P H$
}

\begin{abstract}
Use of the lowest clinically effective dose of postmenopausal hormone therapy conforms to current recommendations and good clinical practice. Although accumulating evidence demonstrates the efficacy and tolerability of low hormone therapy doses, data about their use are limited by a lack of long-term, randomized studies. This review evaluates current evidence on the efficacy, safety, and tolerability of these preparations and their role in menopausal management. ( $\mathrm{J}$ Am Board Fam Med 2009;22: 563-573.)
\end{abstract}

The primary indication for postmenopausal hormone therapy (HT) is to relieve the vasomotor symptoms (hot flashes, night sweats) and vaginal dryness and discomfort that often accompany the menopausal transition and beyond. These symptoms, which are attributed to the natural decline in estrogen during and after menopause, can be remedied with HT. The loss of bone mineral density (BMD) and associated skeletal fragility and increased risk of fracture are also effectively mitigated by HT in postmenopausal women. ${ }^{1-3}$ In women with a uterus, a progestin is used to oppose estrogen-stimulated endometrial proliferation and protect against endometrial cancer.

The safety and tolerability of therapeutic agents must be considered in balance with their clinical efficacy. Reports from the Women's Health Initiative (WHI) trials raised concerns about venous thromboembolic events (VTEs), coronary heart

This article was externally peer reviewed.

Submitted 25 June 2008; revised 3 March 2009; accepted 9 March 2009.

From the Outcomes Research Institute, Geisinger Center for Health Research, Danville, PA.

Funding: Funding to support the preparation of this manuscript was provided, through an unrestricted grant, by Novo Nordisk, Inc.

Conflict of interest: Dr. Langer has received research support from GlaxoSmithKline and has served as a consultant and expert witness for Wyeth, Inc.

Corresponding author: Robert D. Langer, MD, MPH, Jackson Hole Center for Preventive Medicine, US Mail to: PO Box 7416, Jackson, WY 83002, all other couriers: 555 E. Broadway, Suite 108, Jackson, WY 83001 (E-mail: rdlanger@ jhcpm.com). disease (CHD), breast cancer, and stroke in women who were an average of 12 years postmenopause and received estrogen plus progestin (EPT) when compared with women who received placebo ( $\mathrm{Ta}-$ ble 1). ${ }^{2,4-10}$ The estrogen-alone (ET) arm in women without a uterus found increased risks of thromboembolic events and stroke with treatment but no increase in CHD or breast cancer (Table 2). ${ }^{3,411-13}$ Both trials found reduced risks for major fracture and colorectal cancer, the latter particularly in women randomized closer to menopause..$^{2,3}$ However, given that the WHI study population may have been at greater risk for adverse events by virtue of age and years since menopause, the relevance of WHI data to the management of the typical symptomatic woman has been questioned.

Consistent with the most commonly prescribed treatment options at the time the WHI trials were designed, HT doses of $0.625 \mathrm{mg}$ conjugated equine estrogen (CEE) with or without $2.5 \mathrm{mg}$ medroxyprogesterone acetate (MPA) were used. Publication of the initial results from the WHI EPT trial focused attention on the adoption of lower HT doses in clinical practice. ${ }^{14}$ Today, the use of lower starting doses for treatment of postmenopausal symptoms is increasingly recommended. ${ }^{14,15}$

Currently, oral doses as low as $0.3 \mathrm{mg}$ /day of $\mathrm{CEE}$ and $0.5 \mathrm{mg} /$ day of $17 \beta$-estradiol $\left(\mathrm{E}_{2}\right)$ are available to treat menopausal symptoms, and transdermal patches are available with estradiol doses as low as $0.014 \mathrm{mg} /$ day. The purpose of this article is to describe what is known about the efficacy, safety, 
Table 1. Relative Risks of Clinical Events with Estrogen-Progestin Therapy Compared with Placebo in The Women's Health Initiative Randomized Trial ${ }^{2,4-10}$

\begin{tabular}{lccc}
\hline Event (Reference) & Overall Hazard Ratio & Nominal 95\% CI & Adjusted 95\% CI \\
\hline Coronary heart disease (4) & 1.23 & 0.99 to 1.53 & NR \\
Stroke $(4,5)$ & 1.31 & 1.03 to 1.68 & 0.93 to 1.84 \\
Venous thromboembolism (6) & 2.06 & 1.57 to 2.70 & NR \\
Breast cancer, invasive (7, 8) & 1.24 & 1.01 to 1.54 & 0.94 to 1.33 \\
Colorectal cancer (9) & 0.56 & 0.38 to 0.81 & 0.33 to 0.94 \\
Hip fracture (10) & 0.67 & 0.47 to 0.96 & 0.41 to 1.10 \\
Any fracture (10) & 0.76 & 0.69 to 0.83 & NR \\
\hline
\end{tabular}

NR, not reported.

and tolerability of the currently available lowerdose HT formulations as applied to their most common uses.

\section{WHI: Beyond the Preliminary Results}

After the early termination of the WHI trial of combination HT in 2002, initial results indicated that 5 years of standard-dose estrogen $(0.625 \mathrm{mg}$ CEE) plus progestin therapy decreased a woman's risk of fracture and colorectal cancer but increased her risk of VTE, CHD, breast cancer, and stroke. ${ }^{2}$ Although the average age of the participants in the WHI study population was 63 years at the time of study enrollment, with $74 \%$ naïve to HT, the overall risks of HT were said to outweigh the benefits in the study group. These findings were then generalized to all postmenopausal women. However, results from the ET arm of the $\mathrm{WHI},{ }^{3}$ the agestratified analyses from the EPT arm of the WHI, ${ }^{4}$ and the Nurses' Health Study ${ }^{16}$ demonstrated that the risk-benefit profile of standard-dose ET and EPT is more favorable in women closer to the menopausal transition compared with older women, the predominant population in the WHI.

\section{Growing Interest in Lower Hormone Doses}

Using the lowest effective dose of any therapy remains a fundamental tenet of clinical practice and a valuable goal in the treatment of postmenopausal women. Consequently, current guidelines unanimously recommend the use of the lowest effective HT dose. ${ }^{1,17,18}$ Available evidence suggests that lower HT doses may be better tolerated and have fewer adverse effects than standard doses. Using a lower estrogen dose may also reduce the dose of progestin needed for endometrial protection. ${ }^{15,19,20}$ As discussed below, accumulating clinical trial data demonstrate the efficacy of lower HT doses for several indications. However, it is important to acknowledge that the minimally effective dose may not be the same for all women, and that the lowest dose may not address all symptoms in one individual.

In recent years, numerous low-dose estrogen options have been introduced. Currently available low-dose estrogen formulations are listed in Table 3 and include oral CEE 0.45 and $0.3 \mathrm{mg} /$ day; oral ethinyl estradiol $0.025 \mathrm{mg} /$ day; oral esterified estrogens $0.3 \mathrm{mg} /$ day; and transdermal $\mathrm{E}_{2} 0.0375$ and $0.025 \mathrm{mg} /$ day. Low-dose estradiol is available as an

Table 2. Relative Risks of Clinical Events with Unopposed Estrogen Therapy Compared with Placebo Among Patients Without an Intact Uterus in The Women's Health Initiative Randomized Trial ${ }^{3,4,11-13}$

\begin{tabular}{lccc}
\hline Event (Reference) & Overall Hazard Ratio & Nominal 95\% CI & Adjusted 95\% CI \\
\hline Coronary heart disease (4) & 0.95 & 0.78 to 1.16 & NR \\
Stroke (3, 4) & 1.33 & 1.05 to 1.68 & 0.97 to 1.99 \\
Venous thromboembolism (11) & 1.32 & 0.99 to 1.75 & NR \\
Breast cancer, invasive (13) & 0.80 & 0.62 to 1.04 & NR \\
Colorectal cancer (12) & 1.12 & 0.77 to 1.63 & NR \\
Hip fracture (3) & 0.61 & 0.41 to 0.91 & 0.33 to 1.11 \\
Any fracture (3) & 0.70 & 0.63 to 0.79 & 0.59 to 0.83 \\
\hline
\end{tabular}

NR, not reported. 
Table 3. Low-Dose Estrogen Formulations

\begin{tabular}{ll}
\hline & Dose $(\mathrm{mg})$ \\
\hline Oral Formulations & \\
Conjugated equine estrogens & 0.45 \\
& 0.3 \\
$17 \beta$-estradiol $\left(\mathrm{E}_{2}\right)$ & 0.5 \\
Ethinyl estradiol & 0.025 \\
Esterified estrogens & 0.45 \\
& 0.3 \\
Transdermal Formulations & \\
$\mathrm{E}_{2}$ & 0.0375 \\
& 0.025 \\
\end{tabular}

oral formulation of $\mathrm{E}_{2}(0.5 \mathrm{mg} /$ day $)$. An ultra-low dose of transdermal $\mathrm{E}_{2}(0.014 \mathrm{mg} /$ day $)$ is also available, although this dose is approved only for the prevention of postmenopausal osteoporosis. Several combination low-dose oral EPT combinations are also available, including $\mathrm{E}_{2}$ 0.5/norethindrone acetate (NETA) $0.1 \mathrm{mg} /$ day; CEE 0.45/MPA 1.5 $\mathrm{mg} /$ day; and CEE 0.3/MPA $1.5 \mathrm{mg} /$ day.

\section{Efficacy of Lower HT Doses}

The efficacy of lower HT doses has been investigated in many clinical trials; the consensus of these studies is that lower HT doses relieve vasomotor and vulvovaginal symptoms and prevent postmenopausal bone loss with improved tolerability compared with standard doses. ${ }^{14,15,21}$ Representative studies are reviewed below.

\section{Vasomotor Symptoms}

Most women who initiate HT do so to relieve menopausal hot flashes and night sweats. Considerable evidence indicates that lower doses of HT effectively relieve vasomotor symptoms (Table 4). ${ }^{22-30}$ A recent study of 425 women with at least 50 moderate-to-severe hot flashes per week found that low-dose transdermal estradiol $(0.014 \mathrm{mg} /$ day $)$ was effective in reducing vasomotor symptoms compared with placebo. ${ }^{22}$ Oral doses as low as 0.3 $\mathrm{mg}$ daily of esterified estrogens were also effective. ${ }^{24}$ Studies of ET have typically demonstrated differences after approximately 8 to 12 weeks. ${ }^{25-31}$ The Women's Health, Osteoporosis, Progestin, Estrogen trial, which tested CEE at $0.625,0.45$, and $0.3 \mathrm{mg} /$ day, alone and with MPA 2.5, 1.5, and $1.5 \mathrm{mg} /$ day, respectively, demonstrated efficacy for all regimens compared with placebo. ${ }^{25}$ However, the rate of decline in vasomotor symptoms was slightly faster with the progestin-containing regimens. Another study that tested 2 progestin doses in an estrogen-progestin combination $\left(\mathrm{E}_{2} \quad 0.5 /\right.$ NETA $0.1 \mathrm{mg} /$ day and $\mathrm{E}_{2}$ 0.5/NETA $0.25 \mathrm{mg} /$ day) found a significant decrease in the frequency and severity of hot flashes for each active treatment versus placebo after 3 weeks (Figure 1). ${ }^{28}$

In the trial of transdermal regimens reported by Bachmann et al, ${ }^{22}$ participants aged 40 to 71 years (average, 53 years) received $0.023 \mathrm{mg} /$ day $\mathrm{E}_{2}$ with $0.0075 \mathrm{mg} /$ day levonorgestrel, $0.014 \mathrm{mg} \mathrm{E}_{2}$, or placebo for 12 weeks. As mentioned above, $\mathrm{E}_{2}$ $0.014 \mathrm{mg} /$ day significantly reduced the number and severity of vasomotor symptoms compared with placebo (Figure 2). ${ }^{22}$ However, treatment response rates were somewhat greater with $\mathrm{E}_{2} /$ levonorgestrel, suggesting that the concomitant use of a progestin or the slightly higher dose of estrogen provided an advantage in the relief of vasomotor symptoms.

\section{Vulvovaginal Atrophy}

Vasomotor symptoms usually decrease over time; however, vulvovaginal atrophy generally worsens with increasing duration of estrogen deficiency or with increasing time since menopause. Low-dose estrogen therapy has been shown to significantly reduce vaginal atrophy and its associated symptoms in clinical trials. ${ }^{25,28,29,32}$ In general, studies have shown that low-dose estrogen formulations provide greater improvement in vaginal epithelium than placebo but less than that observed with conventional doses of estrogen. ${ }^{32}$ In a recent trial of the impact of 2 low-dose formulations of $E_{2}(0.5 \mathrm{mg} /$ day with either $0.1 \mathrm{mg}$ or $0.25 \mathrm{mg}$ NETA) in a population of younger postmenopausal women who had a low baseline incidence of urogenital symptoms, both therapies resulted in a reduction in vaginal dryness scores and a statistically significant improvement in vaginal maturation and vaginal $\mathrm{pH}$ compared with placebo. ${ }^{28}$ Low-dose regimens of CEE with and without MPA also have been shown to result in statistically significant improvement in vaginal maturation indices. ${ }^{25}$

Local estrogen is also effective for treating urogenital symptoms associated with postmenopausal atrophy of the vagina and the lower urinary tract but they do not provide any vasomotor or osteoporosis benefit. Delivery options include an estrogen vaginal ring, which provides approximately 7.5 


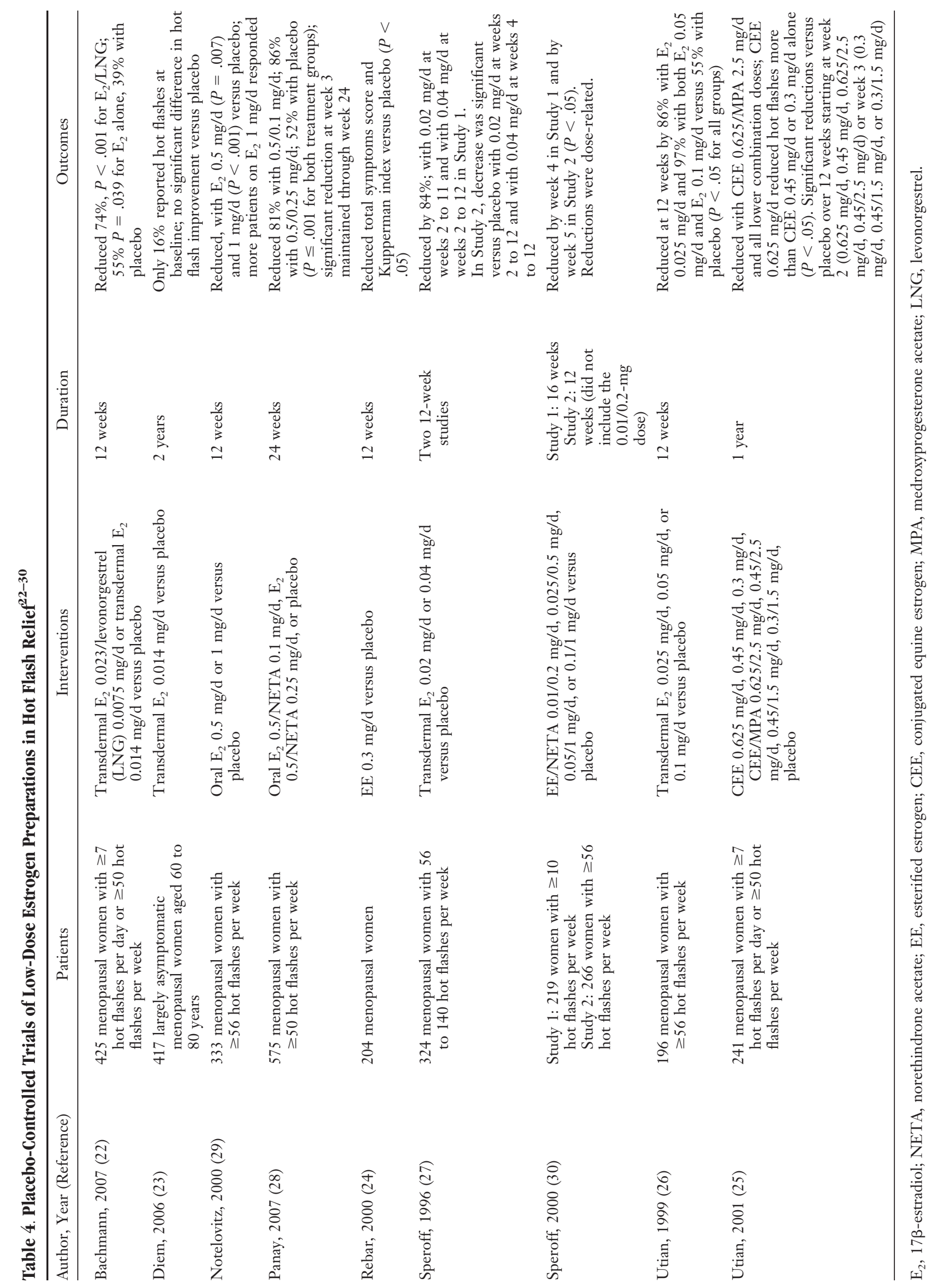

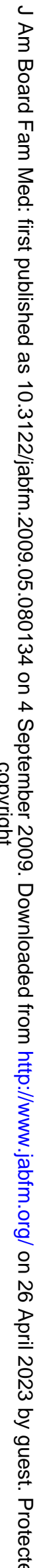




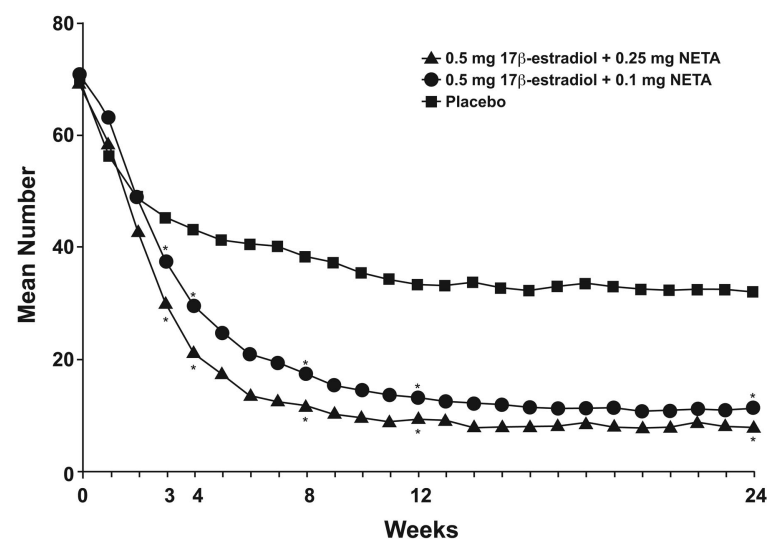

Figure 1. The number of moderate-to-severe hot flashes, by week, with low-dose $E_{2} 0.5 /$ NETA $0.25 \mathrm{mg}$, $E_{2} 0.5 / \mathrm{NETA} 0.1 \mathrm{mg}$, and placebo. *Significantly different from placebo $(P=.001)$. NETA, norethindrone acetate. (Reproduced with permission from Panay N, et al. Ultra-low-dose estradiol and norethisterone acetate: effective menopausal symptom relief. Climacteric 2007;10:120-31. ${ }^{28}$ )

$\mu \mathrm{g}$ of estradiol per day for 3 months of treatment with each insertion; vaginal estradiol tablets, which provide $25 \mu \mathrm{g}$ of estradiol per day; and CEE cream, which provides $0.625 \mathrm{mg} / \mathrm{g} .{ }^{33-35}$ Vaginal estradiol tablets are administered daily for 2 weeks and twice weekly thereafter. ${ }^{35}$ The CEE cream is recom-

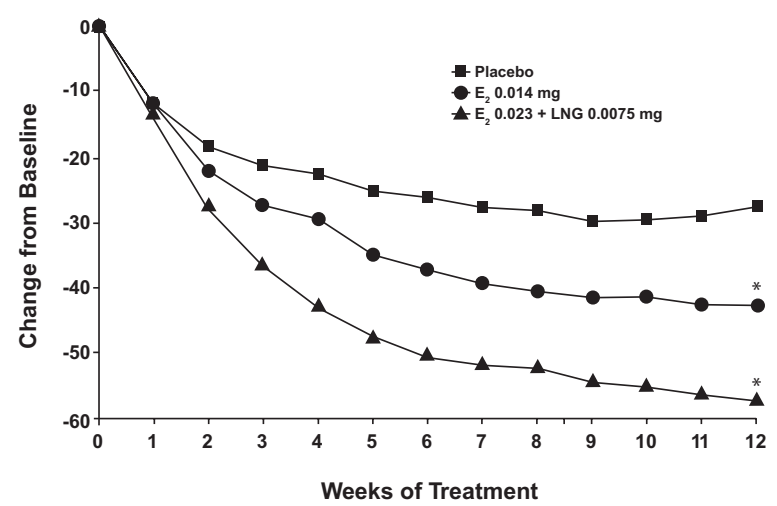

Figure 2. Change from baseline in the mean weekly frequency of moderate-to-severe hot flushes with transdermal $\mathbf{E}_{2} 0.014 \mathrm{mg} / \mathrm{d}$, transdermal $\mathbf{E}_{2} 0.023 \mathrm{mg} /$ d plus levonorgestrel (LNG) $0.0075 \mathrm{mg} / \mathrm{d}$, and placebo. $* P<.001$ vs placebo. (Reproduced with permission from Bachmann $G$, et al. Lowest effective transdermal 17 $\beta$-estradiol dose for relief of hot flushes in postmenopausal women: a randomized controlled trial. Obstet Gynecol 2007;110:771-9. ${ }^{22}$ ) mended for use in a cyclic regimen (daily for 21 days followed by 7 days without treatment) with reassessment at 3- to 6-month intervals. Local treatments differ from other low-dose options in that they do not provide any vasomotor or osteoporosis benefit. According to the North American Menopause Society, progestogen is generally not indicated with local administration of low-dose estrogen for vaginal atrophy. ${ }^{36}$ Data from several studies of low-dose local vaginal estrogen therapy have reported that the risk of endometrial proliferation without the concomitant use of a progestin is low. ${ }^{37,38}$ However, clinical surveillance for potential endometrial effects in women using local estrogen therapy is recommended, a guideline that reinforces the need for using the lowest effective estrogen dose.

\section{Osteoporosis Prevention}

The efficacy of low-dose HT in preventing postmenopausal bone loss has been the focus of numerous studies in recent years. Low doses of HT and lower doses of ET have been shown to effectively prevent bone loss in postmenopausal women. ${ }^{39-41}$ For example, lower doses of oral ET $(0.25$ and 0.50 $\mathrm{mg} /$ day) reduced bone turnover in healthy women older than 65 years of age to a similar degree as that seen with standard-dose therapy $(1.0 \mathrm{mg} /$ day $) .{ }^{39}$

The impact of low-dose HT on BMD and bone turnover also has been evaluated in younger postmenopausal women at risk for rapid bone loss. ${ }^{40,41}$ In the 2-year osteoporosis substudy of the Women's Health, Osteoporosis, Progestin, Estrogen study, low doses of CEE alone (CEE $0.45 \mathrm{mg} /$ day and CEE $0.3 \mathrm{mg} /$ day) and CEE plus MPA (CEE 0.45 , MPA $1.5 \mathrm{mg} /$ day and CEE 0.3 , MPA 1.5 $\mathrm{mg} /$ day) effectively increased BMD and total bone mineral content and reduced markers of bone turnover in postmenopausal women within 4 years of their last menstrual period. ${ }^{40}$ Addition of MPA 2.5 $\mathrm{mg}$ /day to CEE 0.625 or $0.45 \mathrm{mg}$ /day increased spinal BMD in all groups compared with CEE alone.

Speroff et $\mathrm{al}^{41}$ also evaluated the impact of various low doses of ethinyl estradiol (EE) with or without NETA in women within 5 years of menopause. Regimens with EE/NETA produced significant dose-related increases in BMD that were greater than those observed with unopposed EE therapy. ${ }^{41}$ After 24 months, increases in BMD with 
EE/NETA ranged from $5 \%$ to $6 \%$ compared with $0 \%$ to $3 \%$ with unopposed $\mathrm{EE}$.

In summary, low-dose HT provides effective protection against postmenopausal bone loss. The addition of a progestin seems to augment improvements in BMD. ${ }^{40,41}$

\section{Tolerability and Safety of Lower HT Doses}

Clinical trials have demonstrated that lower HT doses provide menopausal symptom relief and osteoporosis prevention with greater tolerability than standard HT doses. Preliminary observational evidence suggests that lower HT doses may also be associated with an improved long-term safety profile compared with standard doses; however, data from large long-term, randomized, controlled trials are lacking.

\section{Endometrial Safety}

The primary goal of progestin use in HT is to reduce the risk of endometrial hyperplasia and endometrial cancer. Progestogens can attenuate some of the favorable effects of estrogens on lipids, ${ }^{42}$ and they are associated with breast tenderness. ${ }^{43}$ Accordingly, the lowest effective dose of this component is important. Because there is a clear doseresponse relationship between the dose of estrogen and the risk of adverse endometrial effects, the progestin dose required for adequate endometrial protection with lower ET doses has been well investigated in clinical trials. These trials demonstrate that lower estrogen doses, when used with adequate doses of progestin (which, in some regimens, are also lower than standard), have an excellent endometrial safety profile. ${ }^{19,20,41}$

However, some experts have suggested that older women using low doses of estrogen may not require the regular use of a progestin. ${ }^{15}$ In one study of postmenopausal women aged 60 to 80 years, participants who received unopposed transdermal estradiol $(14 \mu \mathrm{g} /$ day $)$ had similar rates of endometrial hyperplasia, endometrial proliferation, and vaginal bleeding compared with participants who received placebo during 2 years of treatment. ${ }^{32}$ This may be related to the declining density of endometrial estrogen receptors with advancing age. In contrast, other investigators have noted an increased incidence of endometrial hyperplasia in younger women (aged 40-65 years) after 2 years of treatment with low-dose unopposed estrogen. ${ }^{20}$
Consequently, clinical practice guidelines recommend adding a progestin in women with an intact uterus. ${ }^{1,17,18}$ Although all progestins commonly used in HT provide effective endometrial protection, there is some evidence that micronized progesterone may be better tolerated and may exhibit a reduced proliferative effect on breast tissue compared with other progestins, such as MPA. ${ }^{44,45}$

\section{Bleeding Profile}

One of the most notable benefits of using lower HT doses versus standard doses is an improved uterine bleeding profile. Controlled trials of lower HT doses have reported higher rates of amenorrhea and lower incidences of vaginal bleeding compared with standard doses, particularly in the early cycles of therapy. ${ }^{39,46,47}$ Because the degree and frequency of bleeding is a strong predictor of patient continuation of $\mathrm{HT},{ }^{48,49}$ the reduced bleeding associated with low-dose HT may improve patient compliance and extend its benefits to more women.

\section{Breast Health}

Women using lower EPT doses have a reduced likelihood of experiencing breast tenderness, a relatively common side effect of standard-dose HT, compared with women using standard doses of therapy. ${ }^{25,39}$ The lower progestogen doses made possible by reduced estrogen doses may be important in this regard. ${ }^{25,39}$

The WHI found a modest increased risk of breast cancer in women who received standarddose EPT, but not among women without an intact uterus who received unopposed estrogen (Tables 1 and 2). 2,3 The increase with EPT was widely reported and the null finding with ET is not as well known; it is the rare patient who feels comfortable integrating this information for herself. Consequently, the relationship between lower doses of $\mathrm{HT}$ and breast cancer may be a subject of concern for many women.

The effect of lower doses of estrogen and/or progestin on breast cancer risk is unclear and currently there is minimal evidence that addresses this important clinical issue. A large US prospective observational study reported no increase in breast cancer risk with the use of CEE alone at doses of $0.3,0.625$, and $0.9 \mathrm{mg} /$ day with durations of either $<5$ or $\geq 5$ years; however, there was an inverse trend across the 3 dose levels that approached statistical significance $(P=.06) .{ }^{50}$ Among users of 
combination CEE plus MPA therapy, there was no dose-related breast cancer risk seen for progestin, but daily progestin was associated with an increased risk whereas use for $<2$ weeks per month was not. In contrast, the Collaborative Group on Hormonal Factors in Breast Cancer's reanalysis of data from 51 studies representing nearly 53,000 cases and 108,000 controls did not find an effect of estrogen dose on breast cancer risk. ${ }^{51}$

There has been recent interest in the use of mammographic density as a predictor of breast cancer risk in women using HT because of a reported association between breast density and breast cancer. ${ }^{52}$ Whether breast density changes associated with HT affect breast cancer risk is a subject of debate. ${ }^{53,54} \mathrm{~A}$ recent study by Boyd et $\mathrm{al}^{53}$ directly addressed this question and found no support for this association. Data on more than 1700 postmenopausal women from 3 observational cohorts were combined and it was found that breast density on mammography did not mediate the relationship between HT and breast cancer, although breast density and HT were each independently associated with breast cancer. ${ }^{53}$ Consistent with the nearly universal findings that breast cancer risk is associated with current use of HT and that it declines to a rate comparable with never use after approximately 5 years, ${ }^{51,55}$ the purported association between HT, breast cancer, and mammographic density ${ }^{53}$ or abnormal mammograms ${ }^{7}$ may represent a surveillance effect rather than an etiologic pathway. ${ }^{56,57}$ Nonetheless, a recent study found that low-dose $\mathrm{E}_{2}$ /NETA use had a neutral effect on mammographic breast density. ${ }^{58}$

\section{Cardiovascular Effects}

Venous Thromboembolism

An increased risk of VTE is a well-documented consequence of standard-dose $\mathrm{HT}^{2,3}$ Although preliminary observational evidence indicates that lower HT doses may have a reduced effect on VTE risk compared with standard-dose therapy, ${ }^{59}$ additional research is needed to clarify the impact of lower doses of therapy among HT users. However, recent data indicate that VTE risk may be minimized or eliminated with the use of transdermal estrogen preparations, even at standard doses. ${ }^{60}$ Again, these findings need replication in experimental study designs but, if validated, low-dose transdermal HT could have a safety advantage in this domain.
Stroke

A statistically significant association between HT and stroke, principally in women aged 60 years and older, has been described in the WHI (Tables 1 and 2) and in observational studies. ${ }^{3,5,61-63}$ There are limited data about the risk of stroke with lower HT doses. However, a report from the Nurses' Health Study found that the estrogen dose affected the risk of stroke associated with $\mathrm{HT}^{61}$ In this analysis, CEE doses $\geq 0.625 \mathrm{mg} /$ day were associated with a significantly increased risk of stroke compared with no therapy (relative risk [RR], 1.35; 95\% CI, 1.08-1.68) whereas CEE dosed at 0.3 $\mathrm{mg} /$ day was not linked to an increase in stroke risk (RR, 0.54; 95\% CI, 0.28-1.06). ${ }^{61}$ A more recent analysis of data from this cohort found a strong association between the dose of oral CEE and stroke, with RRs of $0.93,1.54$, and 1.62 for CEE doses of $0.3,0.625$, and $1.25 \mathrm{mg} / \mathrm{d}$, respectively $(P<.001$ for trend $){ }^{62}$

\section{Coronary Heart Disease}

Although results from the EPT arm of the WHI indicated that standard-dose therapy may increase the risk of CHD in older postmenopausal women (Table 1), ${ }^{2,64}$ subsequent analyses of women closer to the menopausal transition in the EPT arm ${ }^{4,16,64}$ and findings from the ET arm (Table 2) ${ }^{65}$ suggest a possible cardioprotective effect of HT in women who initiate treatment near the time of the menopause. ${ }^{4,16}$

A recent analysis of the impact of ET on coronary artery calcification reported that women aged 50 to 59 years at randomization in the WHI who received ET had significantly lower coronary-artery calcium scores after approximately 8 years of treatment compared with those who received placebo (83.1 vs $123.1 ; P=.02) .{ }^{66}$ Moreover, ET use was associated with a significantly lower risk of even mild degrees of coronary-artery calcification (score $<10$ vs $>10$; odds ratio, $0.74 ; P=.04$ ), and the effect was stronger in women with at least $80 \%$ adherence (odds ratio, $0.55 ; P<.001$ ). These data indicate that ET use may be related to a reduced coronary plaque burden and a lower prevalence of subclinical atherosclerotic disease.

Although there are minimal data about the impact of low-dose HT on CHD events, existing evidence indicates that lower doses in younger menopausal women do not adversely affect CHD 
risk. $^{16,67}$ An analysis of data from the Nurses' Health Study reported a nonsignificant reduction in CHD risk with lower estrogen doses (RR for CEE $0.3 \mathrm{mg} /$ day, 0.74; 95\% CI, 0.52-1.06). ${ }^{16}$

\section{Lipid Profile}

Despite the somewhat controversial impact of HT on CHD, the beneficial effects of standard-dose and low-dose HT on the lipid profile are well established. Typically, estrogen decreases serum levels of total cholesterol and low-density lipoprotein cholesterol and increases high-density lipoprotein cholesterol. ${ }^{42}$ Because most of this effect is the result of first-pass metabolism, transdermal estrogen generates smaller changes. ${ }^{68}$ However, oral estrogen increases triglyceride levels, and the addition of a progestin can attenuate some of estrogen's beneficial effects. ${ }^{42}$ The clinical relevance of these lipid changes has been challenged by the WHI finding that HT use did not provide cardioprotection in the overall study population. , $3,64,65$

In general, lipid changes are greater with standard-dose versus low-dose estrogen. ${ }^{69}$ Nevertheless, even low doses of estradiol delivered by vaginal ring for the purpose of treating vaginal atrophy have been found to provide significant improvements in lipid levels, presumably mediated through modest increases in serum estrone sulfate and estradiol levels. ${ }^{70}$ Progestin potency may also play a role: recent evidence suggests that the beneficial effects of EPT on lipid levels are similar to those observed with estrogen alone when norgestimate, a progestin with low androgenicity, is administered intermittently in women with elevated lipids at baseline. ${ }^{71}$ Additional research is needed to determine how lower HT doses affect cardiovascular outcomes.

\section{Talking to Patients about Lower-Dose HT}

When counseling patients about lower-dose HT, it is important to understand their knowledge, concerns, and preferences regarding HT. Integrating that perspective with a clinical understanding of each woman's personal health status sets the stage for a tailored discussion of the benefits and risks of HT as they relate to that woman. The discussion should cover the relative effects of current options, including the possible advantages and risks of lowerdose therapy. Education about low-dose options should focus on available information about efficacy, safety, and tolerability.

As in any counseling encounter, clinicians should encourage patients to discuss their questions and main concerns without interruption. Misperceptions regarding perceived risks of HT or benefits should be clarified, preferably using nontechnical language and examples. Giving patients the opportunity to speak will enhance patient satisfaction and the efficacy of the consultation. Providing clear and concise patient education materials can also be quite helpful. Because the risks of major adverse health events associated with HT for a healthy, early postmenopausal woman are very small $\left(<2\right.$ per 1000 women/year), ${ }^{2}$ decisions about treatment should be guided primarily by the patient's individual preferences and values.

\section{Implications and Conclusions}

Current guidelines recommend that HT should be used at the lowest effective dose consistent with the treatment goals of the individual. Observational data suggest that the use of lower HT doses is not associated with a significant increase in risk of major adverse events; however, there are minimal data from clinical trials on the long-term safety of these preparations. Large, randomized, controlled trials evaluating the long-term efficacy and safety of lowdose HT are urgently needed.

In keeping with the general clinical precept of using the lowest effective dose, lower-dose HT formulations should be considered for the initial management of menopausal symptoms. Patients newly initiated on HT should be encouraged to promptly communicate symptoms and concerns. Dosage or regimen changes should be considered if treatment goals are not met after a suitable interval, typically 1 to 3 months. The use of lower HT doses is supported by evidence demonstrating that they effectively relieve vasomotor symptoms, treat vaginal atrophy, prevent bone loss, provide adequate endometrial protection, and are better tolerated than standard doses.

The author wishes to thank Nicole Cooper (DesignWrite LLC) for writing and editorial assistance.

\section{References}

1. American College of Obstetricians and Gynecologists, Women's Health Care Physicians. ACOG practice bulletin. Clinical management guidelines for 
obstetrician-gynecologists. Number 50, January 2003. Obstet Gynecol 2004;103:203-16.

2. Rossouw JE, Anderson GL, Prentice RL, et al. Risks and benefits of estrogen plus progestin in healthy postmenopausal women: principal results from the Women's Health Initiative randomized controlled trial. JAMA 2002;288:321-33.

3. Anderson GL, Limacher M, Assaf AR, et al. Effects of conjugated equine estrogen in postmenopausal women with hysterectomy: the Women's Health Initiative randomized controlled trial. JAMA 2004;291: 1701-12.

4. Rossouw JE, Prentice RL, Manson JE, et al. Postmenopausal hormone therapy and risk of cardiovascular disease by age and years since menopause. JAMA 2007;297:1465-77.

5. Wassertheil-Smoller S, Hendrix S, Limacher M, et al. Effect of estrogen plus progestin on stroke in postmenopausal women: The Women's Health Initiative: a randomized trial. JAMA 2003;289:2673-84.

6. Cushman M, Kuller LH, Prentice R, et al. Estrogen plus progestin and risk of venous thrombosis. JAMA 2004;292:1573-80.

7. Chlebowski RT, Hendrix SL, Langer RD, et al. Influence of estrogen plus progestin on breast cancer and mammography in healthy postmenopausal women: the Women's Health Initiative randomized trial. JAMA 2003;289:3243-53.

8. Anderson GL, Chlebowski RT, Rossouw JE, et al. Prior hormone therapy and breast cancer risk in the Women's Health Initiative randomized trial of estrogen plus progestin. Maturitas 2006;55:103-15.

9. Chlebowski RT, Wactawski-Wende J, Ritenbaugh C, et al. Estrogen plus progestin and colorectal cancer in postmenopausal women. N Engl J Med 2004; 350:991-1004.

10. Cauley JA, Robbins J, Chen Z, et al. Effects of estrogen plus progestin on risk of fracture and bone mineral density: the Women's Health Initiative randomized trial. JAMA 2003;290:1729-38.

11. Curb JD, Prentice RL, Bray PF, et al. Venous thrombosis and conjugated equine estrogen in women without a uterus. Arch Intern Med 2006;166: 772-80.

12. Ritenbaugh C, Stanford JL, Wu L, et al. Conjugated equine estrogens and colorectal cancer incidence and survival: the Women's Health Initiative randomized clinical trial. Cancer Epidemiol Biomarkers Prev 2008;17:2609-18.

13. Stefanick ML, Anderson GL, Margolis KL, et al. Effects of conjugated equine estrogens on breast cancer and mammography screening in postmenopausal women with hysterectomy. JAMA 2006;295: $1647-57$.

14. Archer DF. Lower doses of oral estrogen and progestogens as treatment for postmenopausal women. Semin Reprod Med 2005;23:188-95.

15. Ettinger B. Rationale for use of lower estrogen doses for postmenopausal hormone therapy. Maturitas 2007;57:81-4.

16. Grodstein F, Manson JE, Stampfer MJ. Hormone therapy and coronary heart disease: the role of time since menopause and age at hormone initiation. J Womens Health 2006;15:35-44.

17. Skouby SO, Al-Azzawi F, Barlow D, et al. Climacteric medicine: European Menopause and Andropause Society (EMAS) 2004/2005 position statements on peri- and postmenopausal hormone replacement therapy. Maturitas 2005;51:8-14.

18. North American Menopause Society. Estrogen and progestogen use in peri- and postmenopausal women: March 2007 position statement of The North American Menopause Society. Menopause 2007;14: $168-82$.

19. Pickar JH, Yeh I-T, Wheeler JE, Cunnane MF, Speroff L. Endometrial effects of lower doses of conjugated equine estrogens and medroxyprogesterone acetate. Fertil Steril 2001;76:25-31.

20. Pickar JH, Yeh I-T, Wheeler JE, Cunnane MF, Speroff L. Endometrial effects of lower doses of conjugated equine estrogens and medroxyprogesterone acetate: two year substudy results. Fertil Steril 2003;80:1234-40.

21. Warren MP. Historical perspectives in postmenopausal hormone therapy: defining the right dose and duration. Mayo Clin Proc 2007;82:219-26.

22. Bachmann GA, Schaefers M, Uddin A, Utian WH. Lowest effective transdermal $17 \beta$-estradiol dose for relief of hot flushes in postmenopausal women: a randomized controlled trial. Obstet Gynecol 2007; 110:771-9.

23. Diem S, Grady D, Quan J, et al. Effects of ultralowdose transdermal estradiol on postmenopausal symptoms in women aged 60 to 80 years. Menopause 2006;13:130-8.

24. Rebar RW, Trabal J, Mortola J. Low-dose esterified estrogens $(0.3 \mathrm{mg} /$ day $)$ : long-term and short-term effects on menopausal symptoms and quality of life in postmenopausal women. Climacteric 2000;3:17682.

25. Utian WH, Shoupe D, Bachmann G, Pinkerton JV, Pickar JH. Relief of vasomotor symptoms and vaginal atrophy with lower doses of conjugated equine estrogens and medroxyprogesterone acetate. Fertil Steril 2001;75:1065-79.

26. Utian WH, Burry KA, Archer DF, et al. Efficacy and safety of low, standard, and high dosages of an estradiol transdermal system (Esclim) compared with placebo on vasomotor symptoms in highly symptomatic menopausal patients. Am J Obstet Gynecol 1999;181:71-9.

27. Speroff L, Whitcomb RW, Kempfert NJ, Boyd RA, Paulissen JB, Rowan JP. Efficacy and local tolerance of a low-dose, 7-day matrix estradiol transdermal system in the treatment of menopausal vasomotor symptoms. Obstet Gynecol 1996;88(4 Pt 1):587-92. 
28. Panay N, Ylikorkala O, Archer DF, Gut R, Lang E. Ultra-low-dose estradiol and norethisterone acetate: effective menopausal symptom relief. Climacteric 2007;10:120-31.

29. Notelovitz M, Mattox JH. Suppression of vasomotor and vulvovaginal symptoms with continuous oral 17ß-estradiol. Menopause 2000;7:310-7.

30. Speroff L, Symons J, Kempfert N, Rowan J. The effect of varying low-dose combinations of norethindrone acetate and ethinyl estradiol (Femhrt) on the frequency and intensity of vasomotor symptoms. Menopause 2000;7:383-90.

31. Gadomska H, Barcz E, Cyganek A, Leocmach Y, Chadha-Boreham H, Marianowski L. Efficacy and tolerability of low-dose transdermal estrogen (Oesclim) in the treatment of menopausal symptoms. Curr Med Res Opin 2002;18:97-102.

32. Johnson SR, Ettinger B, Macer JL, Ensrud KE, Quan J, Grady D. Uterine and vaginal effects of unopposed ultralow-dose transdermal estradiol. Obstetricians Gynecol 2005;105:779-87.

33. Wyeth Pharmaceuticals. Premarin (conjugated estrogens tablets, USP) product information. Philadelphia, PA: Wyeth Pharmaceuticals, 2006.

34. Pharmacia \& Upjohn Company Estring (estradiol vaginal ring $2 \mathrm{mg}$ ) product information. New York, NY: Pharmacia \& Upjohn Company, 2007.

35. Novo Nordisk Inc. Vagifem (estradiol vaginal tablets $25 \mu \mathrm{g}$ ) product information. Princeton, NJ: Novo Nordisk Inc., 2003.

36. North American Menopause Society. The role of local vaginal estrogen for treatment of vaginal atrophy in postmenopausal women: 2007 position statement of The North American Menopause Society. Menopause 2007;14(3 Pt 1):355-69.

37. Bachmann G, Lobo RA, Gut R, Nachtigall L, Notelovitz M. Efficacy of low-dose estradiol vaginal tablets in the treatment of atrophic vaginitis: a randomized controlled trial. Obstet Gynecol 2008;111: 67-76.

38. Manonai J, Chittacharoen A, Theppisai U. Transvaginal color Doppler sonographic assessment of uterus and ovaries in postmenopausal women: the effect of local estrogen treatment. Eur J Obstet Gynecol Reprod Biol 2006;127:222-6.

39. Prestwood KM, Kenny AM, Unson C, Kulldorff M. The effect of low dose micronized $17 \beta$-estradiol on bone turnover, sex hormone levels, and side effects in older women: a randomized, double blind, placebocontrolled study. J Clin Endocrinol Metab 2000;85: 4462-9.

40. Lindsay R, Gallagher JC, Kleerekoper M, Pickar JH. Effect of lower doses of conjugated equine estrogens with and without medroxyprogesterone acetate on bone in early postmenopausal women. JAMA 2002; 287:2668-76.

41. Speroff L, Rowan J, Symons J, Genant H, Wilborn $W$. The comparative effect on bone density, endo- metrium, and lipids of continuous hormones as replacement therapy (CHART Study): a randomized controlled trial. JAMA 1996;276:1397-403.

42. Effects of estrogen or estrogen/progestin regimens on heart disease risk factors in postmenopausal women: Postmenopausal Estrogen/Progestin Interventions (PEPI) Trial. The Writing Group for the PEPI Trial. JAMA 1995;273:199-208.

43. Barnabei VM, Cochrane BB, Aragaki AK, et al. Menopausal symptoms and treatment-related effects of estrogen and progestin in the Women's Health Initiative. Obstet Gynecol 2005;105:1063-73.

44. Greendale GA, Reboussin BA, Sie A, et al. Effects of estrogen and estrogen-progestin on mammographic parenchymal density. Ann Intern Med 1999;130(4 Pt 1):262-9.

45. Cline JM, Soderqvist G, von Schoultz E, Skoog L, von Schoultz B. Effects of hormone replacement therapy on the mammary gland of surgically postmenopausal cynomolgus macaques. Am J Obstet Gynecol 1996;174:93-100.

46. Symons J, Kempfert N, Speroff L. Vaginal bleeding in postmenopausal women taking low-dose norethindrone acetate and ethinyl estradiol combinations. Obstet Gynecol 2000;96:366-72.

47. Archer DF, Dorin M, Lewis V, Schneider DL, Pickar JH. Effects of lower doses of conjugated equine estrogens and medroxyprogesterone acetate on endometrial bleeding. Fertil Steril 2001;75: 1080-7.

48. Johannes CB, Crawford SL, Posner JG, McKinlay SM. Longitudinal patterns and correlates of hormone replacement therapy use in middle-aged women. Am J Epidemiol 1994;140:439-52.

49. Hill DA, Weiss NS, LaCroix AZ. Adherence to postmenopausal hormone therapy during the year after the initial prescription: a population-based study. Am J Obstet Gynecol 2000;182:270-6.

50. Porch JV, Lee IM, Cook NR, Rexrode KM, Burin JE. Estrogen-progestin replacement therapy and breast cancer risk: the Women's Health Study (United States). Cancer Causes Control 2002;13: 847-54.

51. Breast cancer and hormone replacement therapy: collaborative reanalysis of data from 51 epidemiological studies of 52,705 women with breast cancer and 108,411 women without breast cancer. Collaborative Group on Hormonal Factors in Breast Cancer. Lancet 1997;350:1047-59.

52. McCormack VA, dos Santos Silva I. Breast density and parenchymal patterns as markers of breast cancer risk: a meta-analysis. Cancer Epidemiol Biomarkers Prev 2006;15:1159-69.

53. Boyd NF, Martin LJ, Li Q, et al. Mammographic density as a surrogate marker for the effects of hormone therapy on risk of breast cancer. Cancer Epidemiol Biomarkers Prev 2006;15:961-6.

54. Yaffe M, Hendrix S, Pike M, Santen R, Eden J, 
Genazzani A. Is mammographic density, as currently measured, a robust surrogate marker for breast cancer? Gynecol Endocrinol 2005;21(Suppl 1):17-21.

55. Beral V, Million Women Study Collaborators. Breast cancer and hormone-replacement therapy in the Million Women Study. Lancet 2003;362:41927.

56. Foidart JM, Desreux J, Pintiaux A, Gompel A. Hormone therapy and breast cancer risk. Climacteric 2007;10(Suppl 2):54-61.

57. Boyd NF, Rommens JM, Vogt K, et al. Mammographic breast density as an intermediate phenotype for breast cancer. Lancet Oncol 2005;6:798-808.

58. Lundström E, Bygdeson M, Svane G, Azavedo E, Von Schoultz B. Neutral effect of ultra-low-dose continuous combined estradiol and norethisterone acetate on mammographic breast density. Climacteric 2007;10:249-56.

59. Jick H, Derby LE, Myers MW, Vasilakis C, Newton KM. Risk of hospital admission for idiopathic venous thromboembolism among users of postmenopausal oestrogens. Lancet 1996;348:981-3.

60. Canonico M, Oger E, Plu-Bureau, et al. Hormone therapy and venous thromboembolism among postmenopausal women: impact of the route of estrogen administration and progestogens: the ESTHER study. Circulation 2007;115:840-5.

61. Grodstein F, Manson JE, Colditz GA, Willett WC, Speizer FE, Stampfer MJ. A prospective, observational study of postmenopausal hormone therapy and primary prevention of cardiovascular disease. Ann Intern Med 2000;133:933-41.

62. Grodstein F, Manson JE, Stampfer MJ, Rexrode K. Postmenopausal hormone therapy and stroke: role of time since menopause and age at initiation of hormone therapy. Arch Intern Med 2008;168:861-6.
63. Hendrix SL, Wassertheil-Smoller S, Johnson KC, et al. Effects of conjugated equine estrogen on stroke in the Women's Health Initiative. Circulation 2006; $113 ; 2425-34$.

64. Manson JE, Hsia J, Johnson KC, et al. Estrogen plus progestin and the risk of coronary heart disease. N Engl J Med 2003;349:523-34.

65. Hsia J, Langer RD, Manson JE, et al. Conjugated equine estrogens and coronary heart disease: the Women's Health Initiative. Arch Intern Med 2006; 166:357-65.

66. Manson JE, Allison MA, Rossouw JE, et al. Estrogen therapy and coronary-artery calcification. N Engl J Med 2007;356:2591-602.

67. Lobo RA. Evaluation of cardiovascular event rates with hormone therapy in healthy, early postmenopausal women: results from 2 large clinical trials. Arch Intern Med 2004;164:482-4.

68. Adami S, Rossini M, Zamberlan N, Bertoldo F, Dorizzi R, Lo Cascio V. Long-term effects of transdermal and oral estrogens on serum lipids and lipoproteins in postmenopausal women. Maturitas 1993;17:191-6.

69. Lobo RA, Bush T, Carr BR, Pickar JH. Effects of lower doses of conjugated equine estrogens and medroxyprogesterone acetate on plasma lipids and lipoproteins, coagulation factors, and carbohydrate metabolism. Fertil Steril 2001;76:13-24.

70. Naessen T, Rodriguez-Macias K, Lithell H. Serum lipid profile improved by ultra-low doses of $17 \beta$ estradiol in elderly women. J Clin Endocrinol Metab 2001;86:2757-62.

71. Langer RD, Friedman AJ. Effects of $E_{2}$ and $E_{2} /$ norgestimate hormone therapy on elevated baseline lipids. J Reprod Med 2006;51:610-6. 